\title{
Extraction and Characterization of Sugarcane Peel Wax
}

\author{
Mangesh B. Inarkar and S. S. Lele \\ Department of Food Engineering and Technology, Institute of Chemical Technology (Deemed University), Nathalal Parekh Marg, \\ Matunga East, Mumbai 400019, India
}

Correspondence should be addressed to S. S. Lele, dr.smita.lele@gmail.com

Received 10 April 2012; Accepted 11 June 2012

Academic Editors: O. Merah and M. L. Wang

Copyright ( $) 2012$ M. B. Inarkar and S. S. Lele. This is an open access article distributed under the Creative Commons Attribution License, which permits unrestricted use, distribution, and reproduction in any medium, provided the original work is properly cited.

\begin{abstract}
Sugarcane peel is an agrowaste product and contains considerable amount of wax. This has a good technoeconomic potential. In view of this, the present study aims at extraction and characterization of wax from sugarcane peel. The yield of crude wax was $0.95 \%$ on dry weight basis. During Fourier transform-infrared spectroscopy (FT-IR) prominent peaks obtained at 2921.73 and $2851.64(-\mathrm{CH}), 1463.44(-\mathrm{CH} 2), 1376.96(-\mathrm{CH} 3), 1108.4$ and $1170.16(-\mathrm{C}-\mathrm{O}) 3395.60(-\mathrm{OH}), 1710.25(-\mathrm{CHO})$, and 1736.63 $(-\mathrm{COOH})$ indicate presence of alkanes, ketones, alcohols, aldehydes, and carboxylic acids, respectively. Alcohol and hydrocarbon fractions were also found by thin layer chromatography (TLC). Melting point of crude wax was observed to be $62.1^{\circ} \mathrm{C}$. Molecular weight of wax was estimated to be 1706 Dalton. Composition of crude wax found using gas chromatography-mass spectroscopy (GC-MS) was alkanes (28.83\%), ester (66.26\%), fatty acids (4.58\%), aldehyde $(0.11 \%)$, and alcohol $(0.22 \%)$.
\end{abstract}

\section{Introduction}

Sugar cane (Saccharum officinarum L.) is one of the industrially important crops mainly grown in Brazil and India. The global production in the year 2009 was reported to be 1900 million tones of which India produced 285 million tones accounting for $14.9 \%$ [1]. In India, sugarcane supports one of the largest agro-processing industries and more than 6 million farmers are engaged in its cultivation [2]. According to the Indian Institute of Sugarcane Research (IISR) Vision 2030 report, India is expected to increase sugar cane production to 520 million tones. Sugar industry has many byproducts like bagasse, molasses, press mud, and leaves (trash). Sugarcane wax, a whitish to dark yellowish coating on the surface of sugarcane, gets extracted and separated along with press mud during crushing and processing of the cane juice. This wax portion finds applications in cosmetics, paper coating, textiles, fruit and vegetable coating, leather sizing, lubricants, adhesives, polishes, and pharmaceutical industry $[3,4]$. Thus, it can be considered as an alternative to costly carnauba wax, candelilla wax, and chitosan for edible coating applications [5-7]. Sreenivas et al. found ash gourd peel a good source of wax which was used as edible coat for strawberries to enhance their shelf life [8].
Wax from press mud has been extracted and characterized in many earlier studies $[9,10]$. In India, the process of juice extraction from cane at industrial scale involves the unwashed cane being first shredded, pressed followed by filtration of the muddy juice obtained. As a result, wax gets incorporated in the mud and it needs to be extracted and purified before application. On the other hand, sugar cane peels are first removed and then pressed for the juice in case of juice processed for the retail market. Thus, it was comprehended that if one removes peel before juice processing, extraction of wax would be a much easier and cleaner process. The present study was undertaken with aims of extraction and characterization of the sugarcane peel wax.

\section{Materials and Methods}

2.1. Plant Material. Sugarcane peels were collected from some a local juice centre (Figure 1). The waste material was oven dried at $60^{\circ} \mathrm{C}$ for 24 hours. Dried peels were triturated in a mill, packed in polyethylene bags and stored at a dry place for further use. All chemicals used in the study were procured from M/s. Merck Ltd. and M/s. Himedia Ltd., Mumbai, India and were of analytical grade and HPLC grade. 


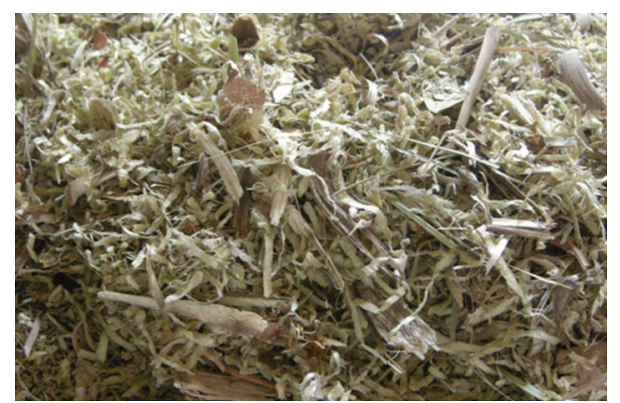

FIgURE 1: Sugarcane peels collected from local juice centre.

2.2. Wax Extraction. Wax was extracted from sugarcane peels as reported by Phukan and Boruah [9]. The process involves soxhlet extraction of peel powder with carbon tetrachloride $\left(\mathrm{CCl}_{4}\right)$ for $8-10$ hours. The solvent was later evaporated using Rota evaporator (Buchi, Switzerland), and the residue primarily contained wax mixtures with some impurities. The residue was dissolved in isopropanol and was refluxed with charcoal for 1-2 hours to remove any undesirable color or pigments present. The extract was then filtered to remove charcoal and evaporated at $60^{\circ} \mathrm{C}$ to obtain crude wax.

\subsection{Analytical Methodologies}

2.3.1. Spectrophotometric Analysis. A known quantity of wax $(0.1 \% \mathrm{w} / \mathrm{v})$ was dissolved in hexane for spectroscopic measurement. The solvent was scanned across wavelength of 200 to $700 \mathrm{~nm}$ by using Helios $\alpha$ spectrophotometer (Thermo Electron Corporation, USA).

2.3.2. Fourier Transform Infrared Analysis. FT-IR spectra of the wax extracts were recorded at $30^{\circ} \mathrm{C}$ using a Perkin Elmer spectrum 100 model (Perkin Elmer, USA). The FT-IR spectrometer was scanned over the frequency range of 4000$450 \mathrm{~cm}^{-1}$ at a resolution of $8 \mathrm{~cm}^{-1}$. The spectrum was collected by using PE spectrum software.

2.3.3. Thin Layer Chromatography Analysis. The wax extracted was subjected to TLC for separation of its various fractions, such as fatty esters, free fatty alcohols, and free fatty acids [11]. Separations were done on aluminum Silufol UV 254 plates (Merck, Mumbai) coated with silica gel layer of $0.25 \mathrm{~mm}$ thickness. Wax dissolved in hexane $(0.1 \% \mathrm{w} / \mathrm{v})$ was applied onto the plates which were developed using the solvent system toluene: acetic acid $(99: 1)$. The spots were visualized using iodine vapor and scanned immediately at $254 \mathrm{~nm}$.

2.3.4. Physicochemical Parameters. The physicochemical parameters like acid value, iodine value, and saponification value were done according to the AOAC Official Method [12].

Molecular weight of the crude wax was determined using gel permeation chromatography (GPC) that was performed with Waters system equipped with a refractive index detector and Waters Styragel column (HR 4THF $(7.8 \times 300 \mathrm{~mm})$, Waters, MA, USA) [13]. A flow rate of $0.8 \mathrm{~mL} \mathrm{~min}^{-1}$ and injection volume of $20 \mu \mathrm{L}$ were used. The analysis was performed with tetrahydrofuran as the mobile phase, and polystyrene standards, covering a broad molar mass range.

The thermal characteristics of the wax sample were measured according to the modified method of Athukorala et al. [14] with a differential scanning calorimeter (DSC60; Shimadzu, Japan). The instrument was calibrated for temperature and heat flow with indium metal $(\mathrm{mp}=$ $\left.156.6^{\circ} \mathrm{C}, \Delta H=28.71 \mathrm{Jg}^{-1}\right)$. In determining the melting point, a flow of nitrogen gas $\left(40 \mathrm{~mL} \mathrm{~min}^{-1}\right)$ was purged in the cell and cooled by liquid nitrogen in a refrigerated cooling system. The sample $(\sim 5 \mathrm{mg})$ was weighed in an aluminum pan and placed in the test cell along with a similar empty reference pan. The sample was heated from -20 to $105^{\circ} \mathrm{C}$ at a rate of $10^{\circ} \mathrm{C} \mathrm{min}{ }^{-1}$, held at $105^{\circ} \mathrm{C}$ for $1 \mathrm{~min}$, and cooled to $25^{\circ} \mathrm{C}$ at $-10^{\circ} \mathrm{C} \mathrm{min}^{-1}$. DSC curves of the last heating cycle were used to determine the melting point range.

2.3.5. Gas Chromatography-Mass Spectroscopy Analysis. The crude wax ( $\sim 4 \mathrm{mg}$ ) was methylated as mentioned by Athukorala et al. [14]. Crude wax was trimethylsilylated with $200 \mu \mathrm{L}$ of bis(trimethylsilyl)trifluoroacetamide and $100 \mu \mathrm{L}$ toluene at $75^{\circ} \mathrm{C}$ for $30 \mathrm{~min}$. The reaction mixture was cooled and concentrated under nitrogen flush and redissolved in hexane.

The analysis was conducted with GC-MS QP 2010 Ultra (Shimadzu, Japan) as mentioned by Deswarte et al. [15]. The GC-MS was equipped with a splitless injector. The capillary column used was Rtx-5MS $(30 \mathrm{~m} \times 0.25 \mathrm{~mm}$ I.D., $0.1 \mathrm{~mm}$ film thickness; Restek). Helium was used as the carrier gas $(1.3 \mathrm{~mL} / \mathrm{min})$. The temperature of the injector was $300^{\circ} \mathrm{C}$. The oven condition was $50^{\circ} \mathrm{C}$ for $1 \mathrm{~min}$, which was increased by $10^{\circ} \mathrm{C} \mathrm{min}^{-1}$ to $280^{\circ} \mathrm{C}$ held for $1 \mathrm{~min}$ followed by $5^{\circ} \mathrm{C} \mathrm{min}{ }^{-1}$ ramping to $320^{\circ} \mathrm{C}$ and held for $10 \mathrm{~min}$. The data was retrieved by using GC-MS solution software and corresponding identification of peaks was done with the help of NIST library.

\section{Results and Discussion}

3.1. Sugarcane Wax Yield. The yield of wax was found to be $0.95 \%(\mathrm{w} / \mathrm{w})$ of dried sugarcane peels. This yield was less compared to wax extracted from press mud (3.50 to $4.10 \%)$ reported by Phukan and Boruah [9]. This can be attributed to the fact that huge quantity of sugarcane juice gets filtered during pressing resulting in press mud having higher concentration of wax, whereas sugarcane peels are produced by shredding surface of sugarcane before crushing, thus affecting the total yield.

3.2. UV-Vis and FT-IR Analysis. Fatty acids, conjugated dienes, and hydroperoxides formed as a result of lipid oxidation absorb UV light at about $232 \mathrm{~nm}$ and conjugated trienes at about $270 \mathrm{~nm}$ [16]. In the UV range (100-400 nm) sugarcane peel wax showed sharp peaks near 230 and $270 \mathrm{~nm}$ indicating the presence of conjugated dienes and trienes (Figure 2). Also, in 535-600 nm range no peaks were found 


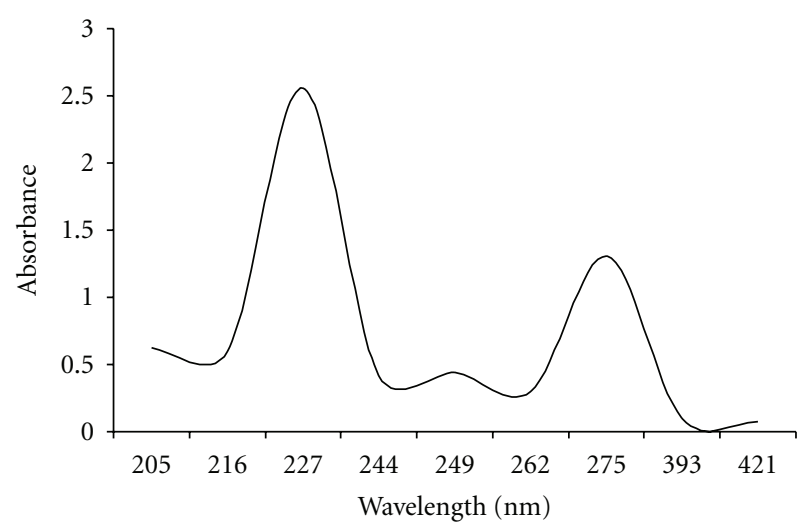

FIgURE 2: UV-Visible spectra of crude wax.

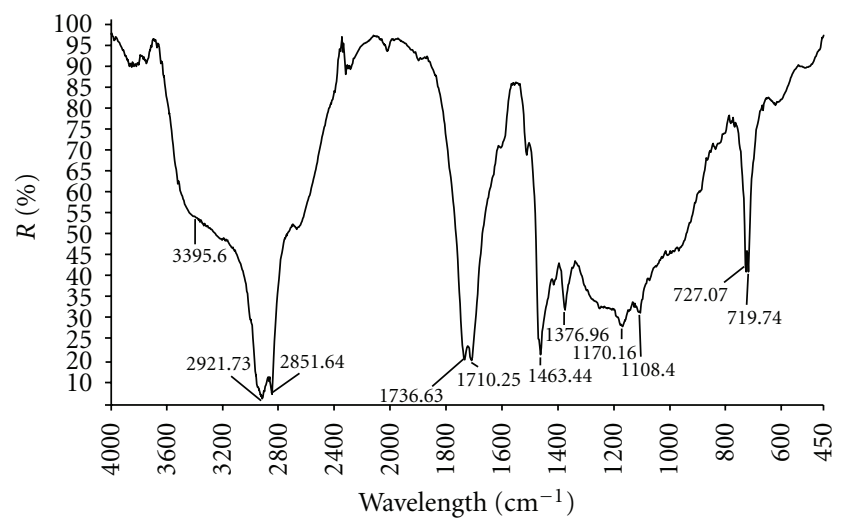

Figure 3: FT-IR spectra of crude wax.

indicating absence of carotenoids [17]. The results are in accordance with Athukorala et al. [14] where wax from (Linum usitatissimum) straw has shown similar pattern.

FT-IR analysis of wax sample revealed the presence of many organic functional groups present in crude wax indicating their respective compounds. Comparison of the absorption frequencies of various organic functional groups mentioned by Nielsen [16] revealed bands at 2921.73 and $2851.64 \mathrm{~cm}^{-1}$ characteristic of $-\mathrm{CH}$ stretch and bend; whereas bands at 1463.44 and $1376.96 \mathrm{~cm}^{-1}$ indicate $-\mathrm{CH}_{2}$ and $-\mathrm{CH}_{3}$ bend. Bands at 3395.60 and 1108.4, $1170.16 \mathrm{~cm}^{-1}$ showed presence of $-\mathrm{OH}$ stretch and $-\mathrm{C}-$ $\mathrm{O}$ stretch, respectively, indicating alcoholic group in the wax sample. Similarly, bands at 1710.25 and $1736.63 \mathrm{~cm}^{-1}$ showed the presence of $-\mathrm{C}=\mathrm{O}$ stretch but represented two different functional group namely aldehydic and carboxylic acid (Figure 3). It was found that FT-IR results were comparable with those reported by Athukorala et al. [14]. Knuutinen and Norrman [18] reported bands at 2918, 2849, 1745 , and $1462 \mathrm{~cm}^{-1}$ for natural and bees wax. Sugarcane peel wax also exhibited similar absorption patterns.

3.3. Thin Layer Chromatography Analysis. Thin layer chromatography revealed bands having $\mathrm{Rf}$ value of 0.29 and 0.85

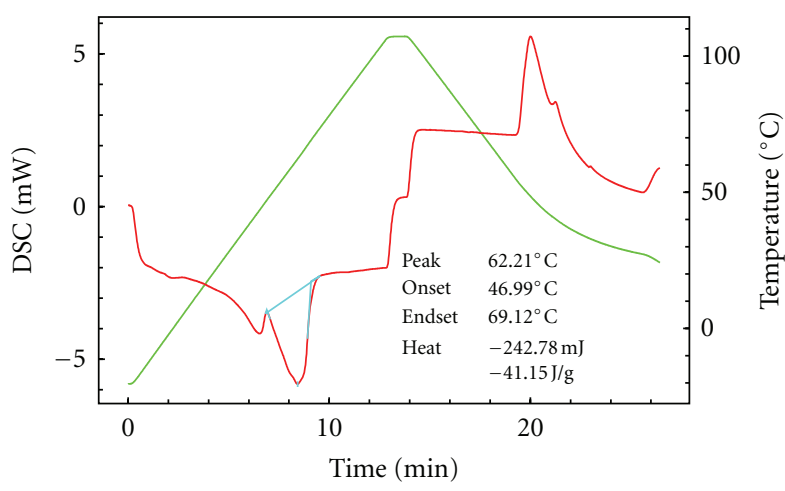

Figure 4: DSC thermogram of crude wax.

which corresponds to alcohol and hydrocarbon fraction [11]. The presence of these compounds was further confirmed by GC-MS result where Isotridecyl alcohol and many fatty acids were found to be present.

3.4. Physicochemical Parameter. Table 1 shows comparative account of physicochemical parameters for wax extracted from sugarcane peels and press mud. Phukan and Boruah [9] reported higher melting point, lower acid value, saponification value, and molecular weight (for both refined and double refined) hard cane sugar wax. In the present study, it was found that wax from sugarcane peels, being crude in nature, shows lower melting point (Figure 4 ) and higher acid value, saponification value, and molecular weight compared to press mud wax.

3.5. Gas Chromatography-Mass Spectroscopy Analysis. This method is suitable for the analysis of compounds which are volatile as such or after derivatization [19]. Gas chromatography has been used for the separation of very long chain fatty acids (VLCFA). Identification of long chain fatty acid from sugarcane wax has been done by Rezanka and Sigler [20], where compounds up to $C_{50}$ were found to be present. Sugarcane peel wax in present study was also subjected to the GC-MS analysis for characterization. Table 2 shows class of compounds present with their retention time and percent composition.

Sugarcane peel wax was predominately founds to contain five main classes of compounds namely, alkanes, fatty acids, alcohol, aldehyde, and ester. Among these, major component was observed to be sec-butyl isothiocyanate. In plants, isothiocyantes are hydrolyzed products of glucosinolates having biological activities including antioxidative, antibacterial, anticancer, gastroprotective, and chemoprotective properties $[21,22]$. The presence of sec-butyl isothiocyanate has been reported in stem, leaf, and seed kernel of Moringa peregrima $[23,24]$.

Another major component was alkane which was found to be $28.83 \%$ of the total extract. It mainly includes compounds like isobutane, triptane, heneicosane, and so forth $\left(\mathrm{C}_{4}-\mathrm{C}_{21}\right)$. Fatty acids in the sample ranged from propanoic 
TABLe 1: Physicochemical parameters of wax.

\begin{tabular}{|c|c|c|c|}
\hline Physicochemical parameter & & Sugarcane peel wax (present study) & Sugarcane press mud wax [9] \\
\hline Color & & Pale yellow & Light yellow \\
\hline Melting point $\left({ }^{\circ} \mathrm{C}\right)$ & & 62.12 & $72-75$ \\
\hline Acid value (mg KOH/g) & & 129.15 & 6.640 \\
\hline Saponification value (mg KOH/g) & & 374.58 & 6.894 \\
\hline \multirow{2}{*}{ Molecular wt } & $\mathrm{Mn}$ & 1665 & - \\
\hline & $\mathrm{Mw}$ & 1706 & 770 \\
\hline
\end{tabular}

TABLE 2: GC-MS profile of crude wax.

\begin{tabular}{|c|c|c|c|c|}
\hline Class of compounds & Name of compounds & Retention time & Area & Percent (\%) composition \\
\hline \multirow[t]{5}{*}{ Alkane } & Isobutane & 1.280 & 133790 & 0.35 \\
\hline & Triptane & 1.767 & 9317828 & 24.22 \\
\hline & Cyclopentane & 1.861 & 785256 & 2.04 \\
\hline & Cyclohexane & 2.034 & 795870 & 2.07 \\
\hline & Heneicosane & 24.55 & 55073 & 0.14 \\
\hline \multirow[t]{11}{*}{ Fatty acid } & Propanoic acid & 1.485 & 298913 & 0.78 \\
\hline & Tetradecanoic acid & 17.182 & 25385 & 0.07 \\
\hline & Hexadecanoic acid & 19.139 & 289207 & 0.75 \\
\hline & 9,12 -Octadecadienoic acid & 20.68 & 193029 & 0.50 \\
\hline & Trans-9-Octadecenoic acid & 20.717 & 188538 & 0.49 \\
\hline & Octadecanoic acid & 20.928 & 175689 & 0.46 \\
\hline & 9-Tetradecenoic acid & 22.391 & 70499 & 0.18 \\
\hline & Tetradecanoic acid & 22.579 & 56098 & 0.15 \\
\hline & Dodecanoic acid & 29.008 & 33706 & 0.09 \\
\hline & Undecanoic acid & 29.134 & 178049 & 0.46 \\
\hline & Malonic acid & 31.125 & 227122 & 0.59 \\
\hline Ester & Sec-Butyl isothiocyanate & 1.716 & 25488899 & 66.26 \\
\hline Aldehyde & Pentadecanol & 29.258 & 43882 & 0.11 \\
\hline Alcohol & Isotridecyl alcohol & 26.528 & 83900 & 0.22 \\
\hline
\end{tabular}

$\left(\mathrm{C}_{3}\right)$ to Octatdecanoic acid $\left(\mathrm{C}_{18}\right)$ contributing $4.51 \%$ of total extract. Mass spectra of some of the major fatty acids are shown in Figure 5. Propanoic acid, the major fatty acid in the sample has antimicrobial effect, indicating that plants must be producing it as defense action against microbial attack. Apart from these major components aldehyde and alcohol (pentadecanol and isotridecyl alcohol) were found to be present.

\section{Conclusion}

The yield of crude wax from sugarcane peel was $0.95 \%$ $(\mathrm{w} / \mathrm{w})$. This study revealed the presence of many classes of compounds like alkane, ester, alcohol, fatty acids, and so forth present in sugarcane peel wax. The major component of wax, that is, sec-butyl isothiocyanates which has many beneficial effects can be utilised for medicinal purpose. Alkane heneicosane finds its application as insect semiochemical. Fatty acids playing significant role in human nutrition were found to be present in the wax. Apart from medicinal, semiochemical and nutritional applications, wax can be used in food preservation as an edible coating for fruits and vegetables. Thus, sugarcane wax has many compounds of biological and industrial importance.

\section{Acknowledgment}

The authors would like to acknowledge the University Grant Commission (UGC), Government of India for financial support. 


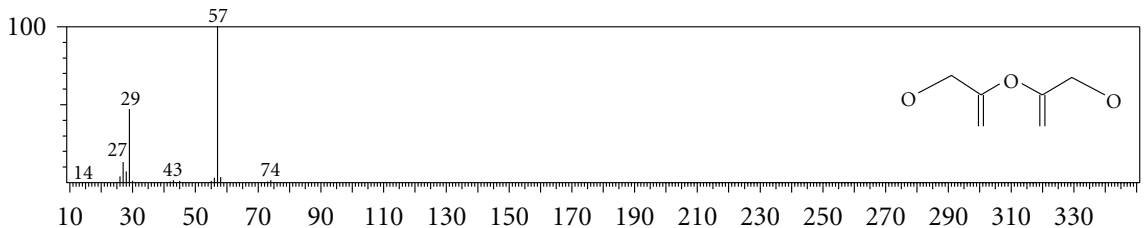

(a)

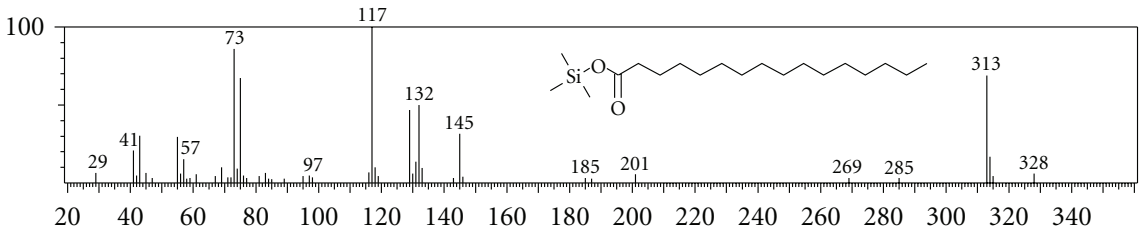

(b)

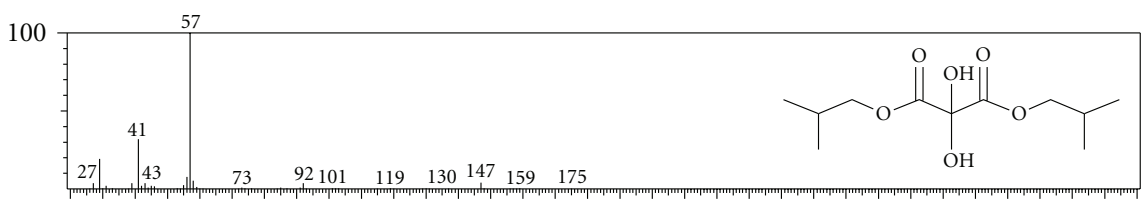

$\begin{array}{lllllllllllllllll}20 & 40 & 60 & 80 & 100 & 120 & 140 & 160 & 180 & 200 & 220 & 240 & 260 & 280 & 300 & 320 & 340\end{array}$

(c)

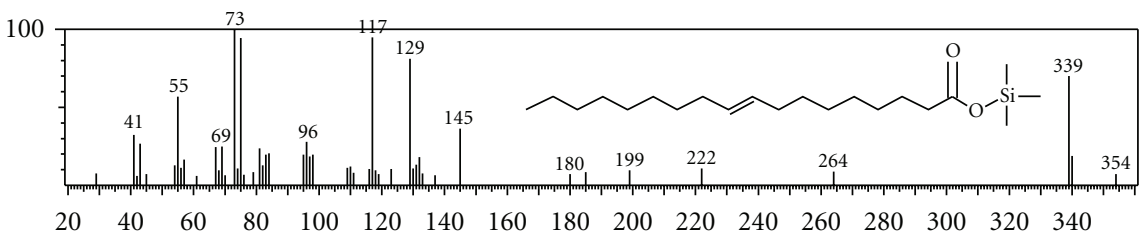

(d)

Figure 5: Mass spectra of major fatty acids (trimethylsilyl derivatives) of sugarcane peel wax. (a) Mass spectrum of propanoic acid. (b) Mass spectrum of hexadecanoic acid. (c) Mass spectrum of malonic acid. (d) Mass spectrum of trans-9-octadecenoic acid.

\section{References}

[1] FAOSTAT, 2010, http://www.fao.org/economic/ess/ess-publications/ess-yearbook/ess-yearbook2010/yearbook2010-production/en/.

[2] Indian Institute of Sugarcane Research (IISR), Vision 2030 July, 2011, http://www.iisr.nic.in/.

[3] P. Georges, M. Sylvestre, H. Ruegger, and P. Bourgeois, "Ketosteroids and hydroxyketosteroids, minor metabolites of sugarcane wax," Steroids, vol. 71, no. 8, pp. 647-652, 2006.

[4] A. K. Taylor, "From raw sugar to raw materials," Chemical Innovation, vol. 30, no. 11, pp. 45-48, 2000.

[5] S. Saucedo-Pompa, R. Rojas-Molina, A. F. Aguilera-Carbó et al., "Edible film based on candelilla wax to improve the shelf life and quality of avocado," Food Research International, vol. 42, no. 4, pp. 511-515, 2009.

[6] C. Amarante, N. H. Banks, and S. Ganesh, "Effects of coating concentration, ripening stage, water status and fruit temperature on pear susceptibility to friction discolouration," Postharvest Biology and Technology, vol. 21, no. 3, pp. 283-290, 2001.

[7] P. J. Chien, F. Sheu, and F. H. Yang, "Effects of edible chitosan coating on quality and shelf life of sliced mango fruit," Journal of Food Engineering, vol. 78, no. 1, pp. 225-229, 2007.

[8] K. M. Sreenivas, K. Chaudhari, and S. S. Lele, "Ash gourd peel wax: extraction, characterization, and application as an edible coat for fruits," Food Science and Biotechnology, vol. 20, no. 2, pp. 383-387, 2011.

[9] A. C. Phukan and R. K. Boruah, "Extraction and evaluation of microcrystalline wax from press mud waste of the sugar industry," Separation and Purification Technology, vol. 17, no. 3, pp. 189-194, 1999.

[10] N. Partha and V. Sivasubramanian, "Recovery of chemicals from pressmud-a sugar industry waste," Indian Chemical Engineering Section A, vol. 48, no. 3, pp. 160-163, 2006.

[11] S. I. Zherebtsov and A. I. Moiseev, "Composition of the wax fraction of bitumen from methylated brown coals," Solid Fuel Chemistry, vol. 43, no. 2, pp. 71-79, 2009.

[12] Association of Official Analytical Chemists, "1990. Method 930.15," in Official Methods of Analyses of the Association of Official Analytical Chemists, Association of Official Analytical Chemists, Washington, DC, USA, 15th edition.

[13] F. M. Mhlongo, A. S. Luyt, and C. G. C. E. van Sittert, "Effect of cross-linking on the thermal stability and molar mass distribution of paraffin waxes," Polymer Degradation and Stability, vol. 73, no. 1, pp. 151-155, 2001.

[14] Y. Athukorala, G. Mazza, and B. D. Oomah, "Extraction, purification and characterization of wax from flax (Linum usitatissimum) straw," European Journal of Lipid Science and Technology, vol. 111, no. 7, pp. 705-714, 2009. 
[15] F. E. I. Deswarte, J. H. Clark, J. J. E. Hardy, and P. M. Rose, "The fractionation of valuable wax products from wheat straw using $\mathrm{CO}_{2}$," Green Chemistry, vol. 8, no. 1, pp. 39-42, 2006.

[16] S. S. Nielsen, Food Analysis, chapter 14 and 23, Springer, 4th edition, 2010

[17] E. Lankmayr, J. Mocak, K. Serdt et al., "Chemometrical classification of pumpkin seed oils using UV-Vis, NIR and FTIR spectra," Journal of Biochemical and Biophysical Methods, vol. 61, no. 1-2, pp. 95-106, 2004.

[18] U. Knuutinen and A. Norrman, "Wax analysis in conservation objects by solubility studies, FTIR and DSC," in Proceedings of the 15th World Conference on Nondestructive Testing, Rome, Italy, 2000.

[19] T. Rezanka, "Very-long-chain fatty acids from the animal and plant kingdoms," Progress in Lipid Research, vol. 28, no. 3, pp. 147-187, 1989.

[20] T. Řezanka and K. Sigler, "Identification of very long chain fatty acids from sugar cane wax by atmospheric pressure chemical ionization liquid chromatography-mass spectroscopy," Phytochemistry, vol. 67, no. 9, pp. 916-923, 2006.

[21] H. Matsuda, M. Ochi, A. Nagatomo, and M. Yoshikawa, "Effects of allyl isothiocyanate from horseradish on several experimental gastric lesions in rats," European Journal of Pharmacology, vol. 561, no. 1-3, pp. 172-181, 2007.

[22] P. Yuan, B. A. Chen, and D. L. Liu, "Anticancer mechanisms and researches of isothiocyanates," Chinese Journal of Natural Medicines, vol. 6, no. 5, pp. 325-332, 2008.

[23] S. Dehshahri, S. Afsharypuor, G. Asgghari, and A. Mohagheghzadeh, "Determination of volatile glucosinolate degradation products in seed coat, stem and in vitro cultures of Moringa peregrine (Forssk.) Fiori," Research in Pharmaceutical Sciences, vol. 7, no. 1, pp. 51-56, 2012.

[24] S. Afsharypuor, G. Asghari, A. Mohagheghzadeh, and S. Dehshahri, "Volatile constitutents of the seed kenrnl and leaf of Moringa peregrine (Forssk.) Fiori, Agricolt. Cultivated in Chabahar (Iran)," Iranian Journal of Pharmaceutical Science, vol. 6, no. 2, pp. 141-144, 2010. 


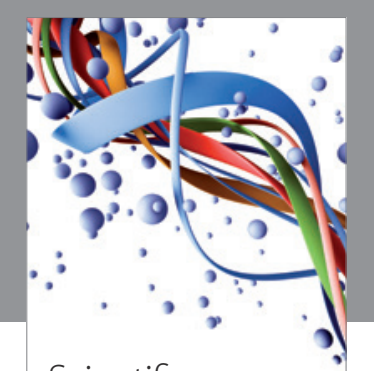

Scientifica
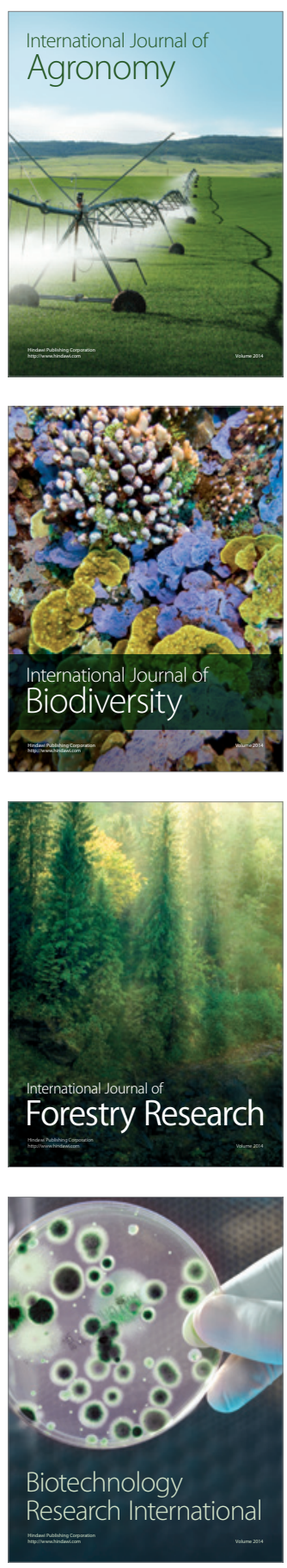
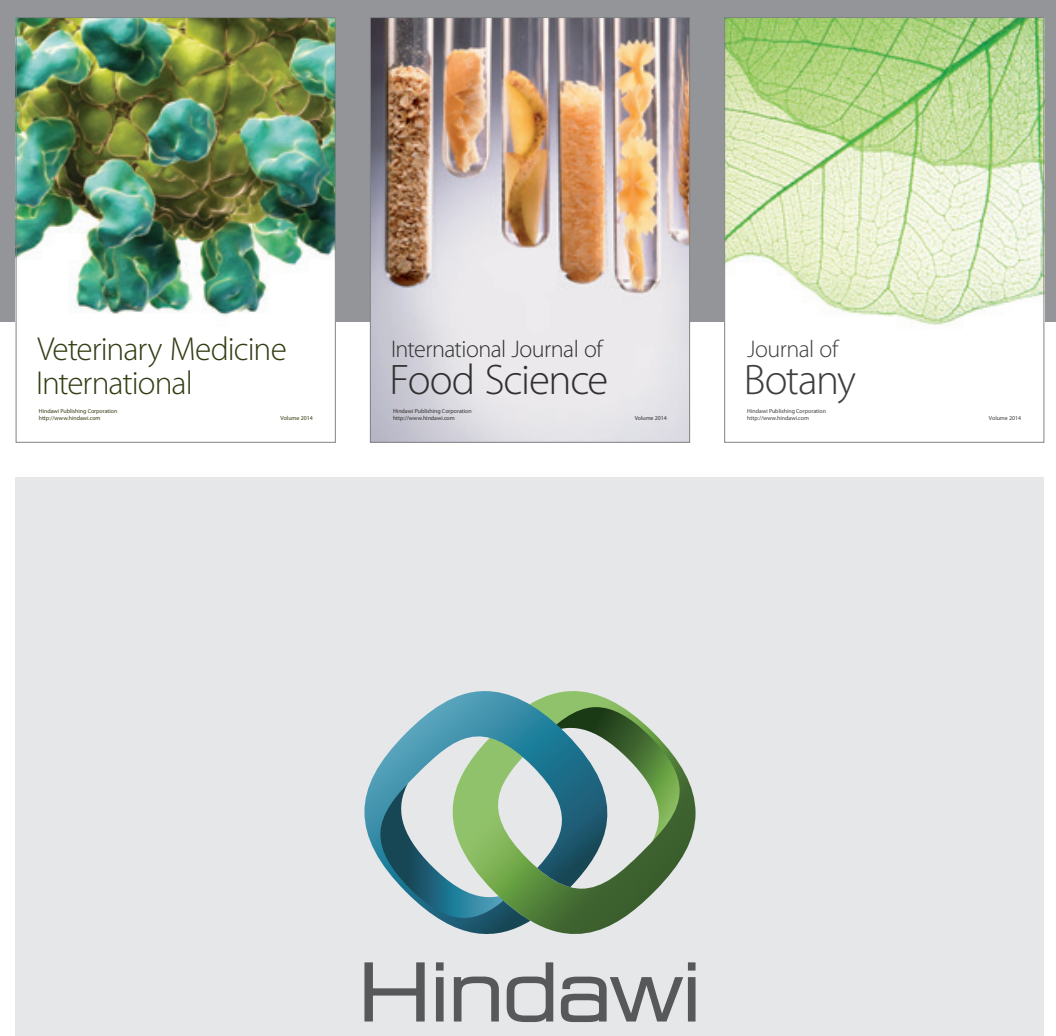

Submit your manuscripts at

http://www.hindawi.com
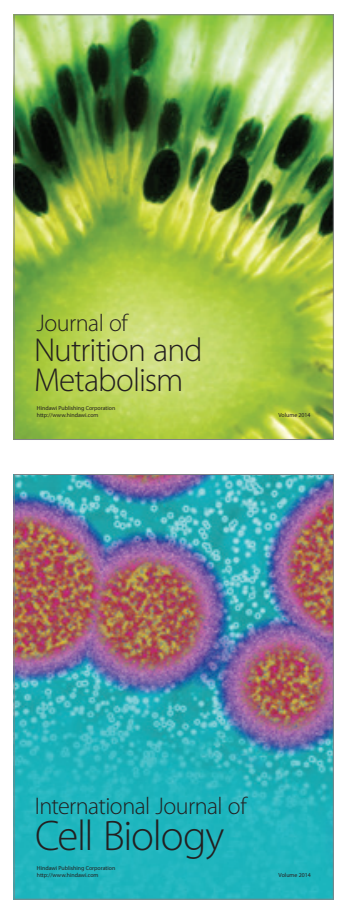
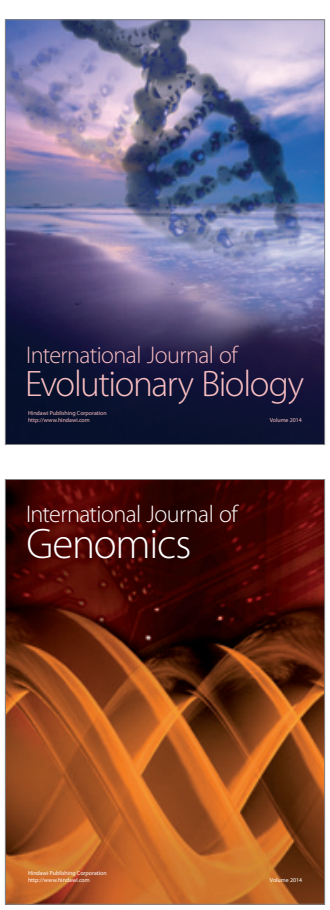
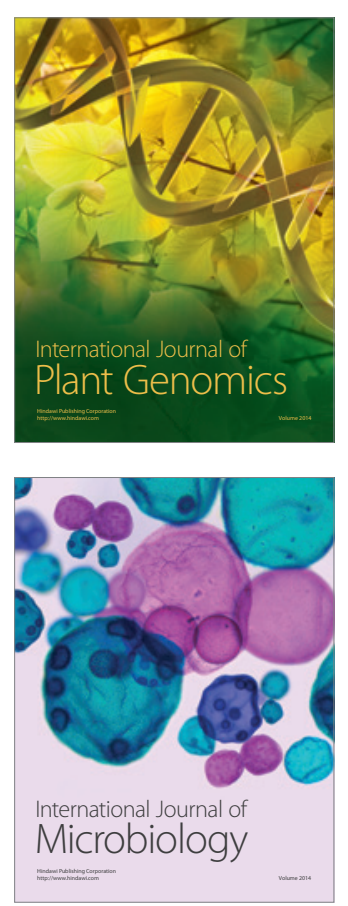

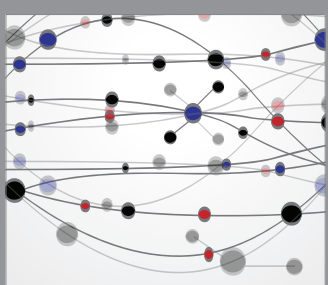

The Scientific World Journal
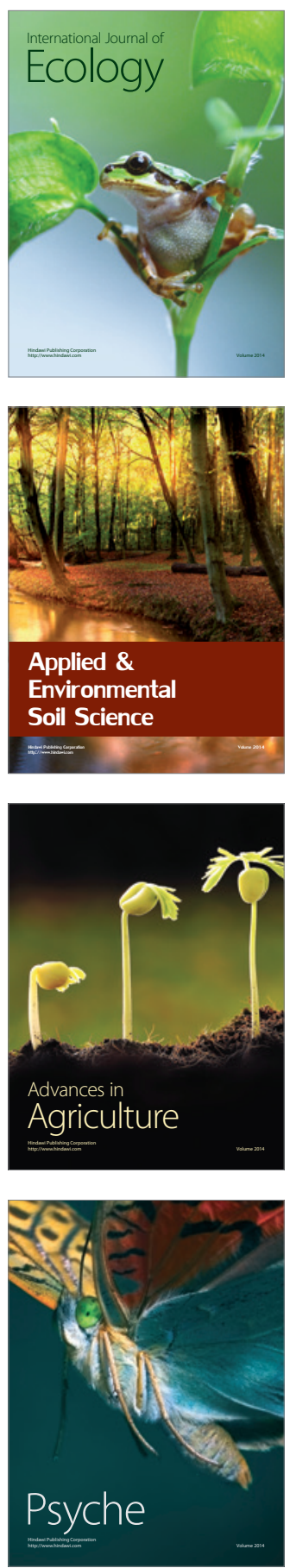